\title{
La tercera ola y la tercera dosis.
}

\author{
The third wave and the third dose.
}

\begin{abstract}
L a tercera ola de COVID-19 ya superó a la segunda en intensidad de contagios. La curva no se aplana ni la pandemia se ha controlado. Las autoridades sanitarias a nivel mundial han explicado que una de las razones por las que la tercera ola no ha sido tan letal como la segunda se debe al avance de la vacunación contra la COVID, pero las mutaciones constantes siguen también desarrollándose mundialmente.

El coronavirus muta y mata. Muta frecuentemente, y las mutaciones se reflejan en modificaciones moleculares, principalmente en las proteínas estructurales del virus. A la fecha son centenares de mutaciones detectadas, principalmente en las regiones de la proteína S (spike), las mutaciones D614G en la espícula o proteína $S$ del SARS-CoV-2 se insertan con mayor capacidad a la proteína receptora ACE2 (angiotensin-converting enzyme 2), localizadas en las superficies celulares, lo que permite introducirse, multiplicarse e infectar a más y más células, tejidos, personas, familias y poblaciones.

En días recientes se han encontrado múltiples variantes de empalme sólo para este gen y se ha visto que las variantes de empalme dACE2 (o MIRb-ACE2) pueden ser inducibles por un interferón.
\end{abstract}

Agustín Zerón*

\section{VARIANTES ALFA $(\alpha), \operatorname{BETA}(\beta)$, $\operatorname{GAMMA}(\gamma), \operatorname{DELTA}(\delta), \operatorname{LAMBDA}(\lambda)$}

Tantas son las variantes que, para evitar mayor «dispersión y confusión», la Organización Mundial de la Salud (OMS) anunció un nuevo sistema que ideó para clasificar a las variantes, o mutaciones más importantes del virus
SARS-CoV-2, por lo que se decidió enumerarlas con el alfabeto griego: $\boldsymbol{\alpha}, \boldsymbol{\beta}, \boldsymbol{\gamma}, \boldsymbol{\delta}$, incluso algunos reportes ya detectan otras variantes lambda (o $\boldsymbol{\lambda}$ ). La aparición de tantas suponía un mayor riesgo para la salud pública mundial, a finales del año 2020, se inició una forma para denominarlas en dos categorías más específicas: «variante de interés» (VOI - variant of interest) y «variante preocupante» (VOC - variant of concern), con el fin de priorizar el seguimiento e investigación a escala global y, en última instancia, orientar las estrategias sanitarias ante a la pandemia de COVID-19 (Tabla 1).

La variante $\lambda$ o lambda, registrada por primera vez en Perú en el 2020, se ha expandido por Sudamérica y está catalogada por la OMS como una variante de interés, a diferencia de las cepas alfa, beta, gamma y delta, que pertenecen a la categoría de variantes preocupantes. Las cuatro primeras combinan múltiples mutaciones en diferentes puntos de sus genomas. Mientras que las VOC, o variante de preocupación, son variantes con una clara evidencia de correlación clínica con el aumento en la transmisibilidad, probabilidad de COVID grave, eficacia reducida de los tratamientos y fallas con las vacunas, incluso fallas en la detección del diagnóstico.

Otra variante de gran consecuencia es cuando existe una clara evidencia de que las medidas de prevención o las contramedidas médicas (MCM - measures or medical countermeasures) han reducido significativamente la efectividad en relación con las variantes que circulaban anteriormente.

Hasta ahora, parece ser que las vacunas desarrolladas seguirán siendo eficaces contra estas primeras cuatro va-

* Especialista en Endoperiodontología. Editor en Jefe de la Revista ADM. México.

Citar como: Zerón A. La tercera ola y la tercera dosis. Rev ADM. 2021; 78 (4): 186-188. https://dx.doi.org/10.35366/101071

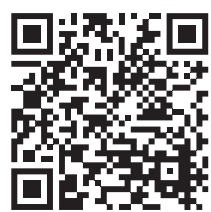




\begin{tabular}{|c|c|c|c|c|c|c|}
\hline $\begin{array}{l}\text { WHO } \\
\text { label }\end{array}$ & $\begin{array}{l}\text { Linajes } \\
\text { Pango* }\end{array}$ & $\begin{array}{l}\text { Clado } \\
\text { GISAID** }\end{array}$ & $\begin{array}{l}\text { Código } \\
\text { filogénico }\end{array}$ & $\begin{array}{l}\text { Cambios de aminoácidos } \\
\text { adicionales monitoreados }+\end{array}$ & $\begin{array}{c}\text { Muestras documentadas } \\
\text { más antiguas }\end{array}$ & $\begin{array}{c}\text { Fecha de } \\
\text { designación }\end{array}$ \\
\hline $\begin{array}{c}\text { Alfa } \\
\alpha\end{array}$ & B.1.1.7 & GRY & 20I (V1) & $\begin{array}{l}+\mathrm{S}: 484 \mathrm{~K} \\
+\mathrm{S}: 452 \mathrm{R}\end{array}$ & $\begin{array}{l}\text { Reino Unido } \\
\text { Sep-2020 }\end{array}$ & 18-Dic-2020 \\
\hline $\begin{array}{c}\text { Beta } \\
\beta\end{array}$ & $\begin{array}{c}\text { B.1.351 } \\
\text { B.1.351.2 } \\
\text { B.1.351.3 }\end{array}$ & GH/501Y.V2 & $20 \mathrm{H}(\mathrm{V} 2)$ & $+\mathrm{S}: \mathrm{L} 18 \mathrm{~F}$ & $\begin{array}{l}\text { Sudáfrica } \\
\text { May-2020 }\end{array}$ & 18-Dic-2020 \\
\hline $\begin{array}{c}\text { Gamma } \\
\gamma\end{array}$ & $\begin{array}{c}\text { P.1 } \\
\text { P.1.1 } \\
\text { P.1.2 } \\
\text { P.1.4 } \\
\text { P.1.6 } \\
\text { P.1.7 }\end{array}$ & GR/501Y.V3 & 20J (V3) & $+\mathrm{S}: 681 \mathrm{H}$ & $\begin{array}{c}\text { Brasil } \\
\text { Nov-2020 }\end{array}$ & 11-Ene-2021 \\
\hline $\begin{array}{l}\text { Delta } \\
\delta\end{array}$ & $\begin{array}{c}\text { B.1.617.2 } \\
\text { AY.1 } \\
\text { AY.2 } \\
\text { AY.3 } \\
\text { AY.3.1 }\end{array}$ & G/478K.V1 & $21 \mathrm{~A}$ & $+\mathrm{S}: 417 \mathrm{~N}$ & $\begin{array}{c}\text { India } \\
\text { Oct-2020 }\end{array}$ & $\begin{array}{c}\text { VOI: } \\
\text { 4-Abr-2021 } \\
\text { VOC: } \\
\text { 11-May-2021 }\end{array}$ \\
\hline
\end{tabular}

*Los nombres del linaje Pango comprenden un prefijo alfabético y un sufijo numérico. ** GISAID es una iniciativa científica global y una fuente primaria establecida en 2008 que brinda acceso abierto a los datos genómicos de los virus de la influenza y ahora del coronavirus SARS-CoV-2. + Cambios notables de la proteína S (spike) en aminoácidos de bajo monitoreo, que actualmente se informan en una minoría de muestras secuenciadas.

VOI = variant of interest; $\mathrm{VOC}=$ variant of concern.

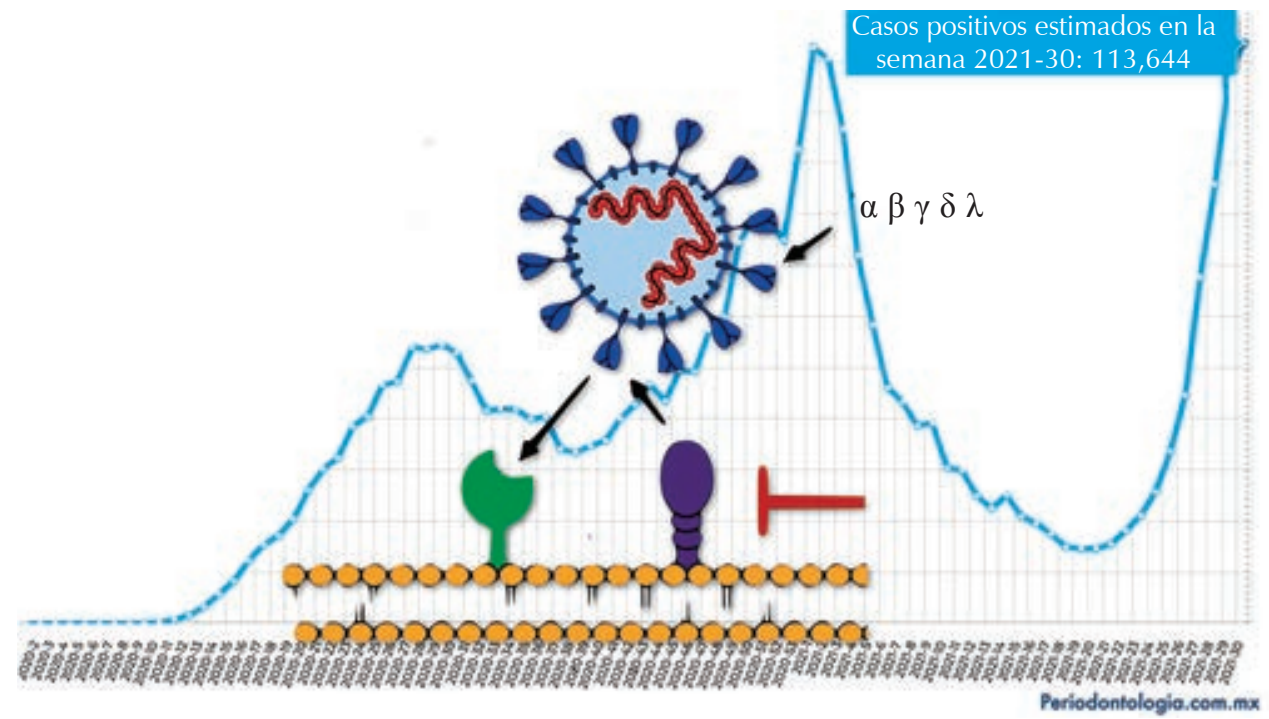

Figura 1:

Hasta el último reporte de la Secretaría de Salud, en esta tercera ola de la pandemia, México registró 23 mil 642 nuevos casos de COVID-19 en las últimas 24 horas, sumando un total de 3 millones 91 mil 971 casos confirmados en el país.

riantes, aunque existe cierta inquietud entre la comunidad científica por la disminución de la eficacia. La mayoría de estas mutaciones no tiene consecuencias sobre el curso de la pandemia, pero la preocupación existe porque las mutaciones han dado una mayor virulencia, mayor transmisibilidad, reinfecciones, escape de la inmunidad, incluso una posible ineficacia de las vacunas. Un corona- virus sin células donde albergarse es sólo porción de letras de RNA, incapaces de contar una historia, sin embargo, a partir de cada persona infectada se producen millones de nuevos virus, que generarán nuevas variantes y una nueva historia natural de pandemia. Es una batalla continua entre genes de resistencia y factores de virulencia, los virus ancestralmente han jugado un papel muy importante en 
la ecología global del planeta Tierra, y esto es simplemente el potencial en la presión evolutiva.

La OMS pidió posponer las terceras dosis o refuerzo hasta finales de septiembre, para permitir que al menos $10 \%$ de la población de todos los países pueda vacunarse. Sin embargo, algunos países desarrollados ya aprobaron la tercera dosis de refuerzo para ciertas poblaciones de mayor riesgo, o al menos anunciaron campañas para aplicar la dosis de refuerzo. La India y otros países también necesitarán planificar una tercera dosis anti-COVID-19 para su población en el 2022, para contrarrestar las diversas mutaciones del SARS-CoV-2. La sugerencia de los científicos surge cuando en varios países están luchando en el frente de la vacunación, a pasos lentos, demasiado lentos, y con limitadas dosis aplicadas a la fecha, como en México, donde no hay ninguna variante en las estrategias de contención pandémica (Figura 1).

\author{
Correspondencia: \\ Dr. Agustín Zerón \\ E-mail: periodontología@hotmail.com
}

